\title{
Microclimatic responses to different thinning intensities in a Japanese cedar plantation of northern Taiwan
}

\author{
Shih-Hao Weng ${ }^{\text {a,b }}$, Shing-Rong Kuo ${ }^{\text {a }}$, Biing T. Guan ${ }^{\text {a,* }}$, Tsung-Yi Chang ${ }^{\text {a }}$, \\ Hsin-Wu Hsu ${ }^{\text {a }}$, Chieh-Wen Shen ${ }^{b}$ \\ ${ }^{\text {a }}$ School of Forestry and Resource Conservation, National Taiwan University, Taipei 10617, Taiwan \\ ${ }^{\mathrm{b}}$ Experimental Forest, National Taiwan University, Chu-Shan 55750, Taiwan
}

Received 8 July 2006; received in revised form 24 October 2006; accepted 29 December 2006

\begin{abstract}
To assess the effects of thinning intensities on, and to reveal the temporal trends of, the short-term microclimates in a Japanese cedar (Cryptomeria japonica D. Don) plantation in a montane region of northern Taiwan, we monitored air and soil temperatures, air and soil temperature ranges, soil water potential, and ambient air water pressure deficit within the plantation over a 2-year period. The thinning experiment consisted of three thinning intensities (weak, moderate, and strong) and a control (unthinned). We used a set of semiparametric smoothing spline and linear mixed-effects models to analyze the monthly averages of the six variables. The results showed that the temporal trends of the six variables mainly reflected the regional climatic patterns during the study period and the topographic effects. Averaged over the 2-year period, the strongly thinned stand had significantly higher air and soil temperatures than that for the other three treatments. All the thinned stands had higher average air temperature ranges than that for the control, and the average of the strongly thinned stand was significantly higher than that for the other two thinning treatments. The air temperature ranges of the thinned stands, however, returned almost to the pre-thinning stage at the end of the monitoring period. For soil temperature range, the strongly thinned stand had a significantly higher average than that for the other three stands. Structural heterogeneity created by thinning also led to greater month-to-month variations in air and soil temperature ranges for the thinned stands. As a combination of thinning and its aspect, the moderately thinned stand had the highest soil water potential, followed by the strongly thinned stand. The thinned stands all had higher average soil water potential than for the control in a severe summer drought that occurred during the study period. For water vapor pressure deficit, no significant thinning effect was detected, probably because the study site was located within the cloud belt of northern Taiwan. This study has demonstrated that we can understand better how thinning truly affects microclimates by separating the influences that are due to higher-level climatic factors from those due to thinning. Implications of the effects of different thinning intensities were also addressed.
\end{abstract}

(C) 2007 Elsevier B.V. All rights reserved.

Keywords: Air temperature; Soil temperature; Soil water potential; Water vapor pressure deficit

\section{Introduction}

Promotion of biodiversity has become an important management objective for plantation forests over the past decade, and thinning is viewed as one of the most effective tools to achieve it (Sullivan et al., 2001, 2002, 2005; Lindh and Muir, 2004; Hagar et al., 2004). Monitoring the microclimatic responses is an integral part of any thinning experiment. Besides adjusting the spatial structure of a stand, thinning can promote biodiversity by modifying the microclimates within

\footnotetext{
* Corresponding author. Tel.: +8862 33664628; fax: +886223639247. E-mail address: btguan@ntu.edu.tw (B.T. Guan).
}

the thinned stands. In turn, this can allow the development of a more diverse flora and fauna (Muir et al., 2002; Hanley, 2005; MacCracken, 2005). By changing microclimatic conditions, thinning can also alter important ecophysiological and ecosystem processes (Aussenac, 2000; Thibodeau et al., 2000; Bauhus et al., 2001).

Factors controlling the microclimate within a forest are hierarchical in nature (Aussenac, 2000). Higher-level factors, such as regional climate, site topography, etc., assert their influences on microclimates first (Holst et al., 2004; Holst et al., 2005). The effects of lower-level factors, such as soil and vegetation characteristics, are added subsequently. Microclimatic responses after thinning will thus reflect the effects of the regional climatic trends over the monitoring period, thinning, 
and possibly their interactions. Therefore, to understand better how thinning truly affect microclimates, we should separate and evaluate the relative importance of those influences.

This study was a part of a comprehensive project to promote the biodiversity of even-aged plantation forests of Taiwan. The objective of this study is to assess the effects of thinning intensity on, and to reveal the temporal response trends of, the monthly averages of six microclimatic variables over a 2-year period.

\section{Materials and methods}

\subsection{Study site}

The thinning experiment was conducted in a 30-year old Japanese cedar (Cryptomeria japonica D. Don) plantation located in the Guanwu area $\left(24^{\circ} 30^{\prime} \mathrm{N}, 121^{\circ} 07^{\prime} \mathrm{E}\right)$ of northern Taiwan. The elevation of the study site was between 2000 and $2200 \mathrm{~m}$, which is within the cloud belt of northern Taiwan. Based on records from the nearby Guanwu Weather Station $\left(24^{\circ} 30^{\prime} \mathrm{N}, 121^{\circ} 06^{\prime} \mathrm{E}\right.$, elevation $\left.2087 \mathrm{~m}\right)$, the annual average temperature for the area is about $12.1{ }^{\circ} \mathrm{C}\left(6.3{ }^{\circ} \mathrm{C}\right.$ in January, $16.2^{\circ} \mathrm{C}$ in July) with an annual average precipitation about $3200 \mathrm{~mm}$. The precipitation in the region is mainly orographic in origin and distributes unevenly throughout the year (wet in summer and dry in winter) with a significant amount of precipitation during the summer due to typhoons.

The average annual temperatures during the monitoring period (February 2002-January 2004) were the about same as the long-term average (about $12.6{ }^{\circ} \mathrm{C}$ for both 2002 and 2003). The amounts of precipitation, however, were significantly lower than the average. The total amount of precipitation in the study site was $2762 \mathrm{~mm}$ in 2002, and $1865 \mathrm{~mm}$ in 2003 . The significantly lower amounts of precipitation were due mainly to the lack of typhoons visiting the northern Taiwan region during those 2 years. In addition, both November and December of 2003 were the driest months ever recorded in the study area (7.0 and $1.5 \mathrm{~mm}$ for November and December, respectively).

The average slope of the study site was $20-22^{\circ}$, and the soil of the study area was sandy- or silt-loam with an average O/A layer depth about $8 \mathrm{~cm}$ (Weng, 2004).

\subsection{Thinning experiment}

The experiment had three thinning intensities (strong, moderate, and weak) and a control (unthinned). The area of the experiment was about 40 ha and the size of each treatment varied from 5 to 14 ha. The aspect of the study area was mainly northwest, except for the moderately thinned stand where it was north. The experiment was unreplicated due to operational constraints. All thinning treatments used the traditional thinning-from-below approach. The thinning operation was conducted from October to December, 2001. The average numbers of residual stems and average residual basal areas (in parentheses) per hectare after thinning were $500\left(32.2 \mathrm{~m}^{2}\right), 680$ $\left(53.0 \mathrm{~m}^{2}\right), 960\left(70.8 \mathrm{~m}^{2}\right)$, and $1540\left(82.8 \mathrm{~m}^{2}\right)$ for the strong, moderate, weak, and control treatments, respectively. Four
0.05 ha circular plots were established within each treatment to monitor changes in microclimates, plant species richness, and soil properties.

\subsection{Microclimatic monitoring}

Devices were set up for monitoring microclimatic variables in January, 2002, at the center of each 0.05 ha plot. The built-in sensors of WatchDog Model 450 data logger (Spectrum Technologies, East Plainsfield, IL, USA) were used to record air temperature $\left({ }^{\circ} \mathrm{C}\right)$ and relative humidity $(\%)$ at each monitoring point. The recording range of the temperature sensor was -20 to $70{ }^{\circ} \mathrm{C}\left( \pm 0.7{ }^{\circ} \mathrm{C}\right)$, and the recording range of the relative humidity sensor was $20-100 \%$ (at $5{ }^{\circ} \mathrm{C} \sim 50{ }^{\circ} \mathrm{C}$, $\pm 3 \%$ ). The data logger was shielded from direct radiation and rain, and was placed at a height of $70 \mathrm{~cm}$ above the soil surface (about $20 \mathrm{~cm}$ above the average ground vegetation height). Although the height was lower than the standard height for monitoring air temperature, we believed that height to be biologically more relevant than the standard height. We will still refer to that temperature as air temperature in this study. The soil temperature was monitored using an external soil temperature sensor (model 3667, Spectrum Technologies, East Plainsfield, IL, USA) that had a recording range of -30 to $100{ }^{\circ} \mathrm{C}\left( \pm 0.7^{\circ} \mathrm{C}\right)$. The soil water potential was monitored using a Watermark soil moisture sensor (model 6450WD, Spectrum Technologies, East Plainsfield, IL, USA) with a recording range of 0 to $-200 \mathrm{kPa}$. Both soil temperature and moisture sensors were buried $10 \mathrm{~cm}$ below the soil surface and were connected to the data logger. All sensors were calibrated prior to field installation. The four microclimatic variables were automatically recorded every $2 \mathrm{~h}$, beginning on February 1, 2002, and ending on January 31, 2004. Data were retrieved every 2 weeks.

After data were retrieved, any inconsistent data were discarded. Such data were mainly due to the malfunctions of sensors. Those sensors were replaced. To calculate ambient air water vapor pressure deficit $(\mathrm{kPa})$, we first calculated the saturated water vapor pressures $\left(e_{\mathrm{s}}\right)$ based on the empirical equation of Buck (1981). Ambient air water vapor pressures $(e)$ were then derived from the observed relative humidities and $e_{\mathrm{s}}$. Water vapor pressure deficit was defined as the difference between the $e_{\mathrm{s}}$ and $e$. Later, for each variable at each monitoring point, a monthly average was calculated. In addition, we also derived monthly average air and soil temperature ranges from the daily air and soil temperature data.

\subsection{Statistical analyses}

In this study, we were particularly interested in the effects of different thinning intensities on the monthly averages of air and soil temperatures (AT and ST, respectively), air and soil temperature ranges (ATR and STR, respectively), soil water potential (SWP), and water vapor pressure deficit (VPD).

A set of semiparametric smoothing spline models (Wahba, 1990; Ke and Wang, 2001) and a linear mixed-effects model (Pinheiro and Bates, 2000) were used to analyze the effects of thinning intensity on, and to reveal the temporal trends of, the 




Fig. 1. Observed mean (O), overall mean (dashed line), and model fitted (solid line) monthly average air temperatures from February 2002 to January 2004 for the four thinning treatments. Air temperatures were measured at $70 \mathrm{~cm}$ above the soil surface. For each month, the overall mean is the average of the observed means.

six microclimatic variables. The variable STR was analyzed by a linear mixed-effects model. The remaining five variables were analyzed by semiparametric smoothing spline models. The concept of smoothing splines can be viewed as a compromise between a model's ability to fit data and the model's smoothness (Green and Silverman, 1994; Eubank, 1999). The advantage of using smoothing splines is in the approach's flexibility and ability to approximate the underlying nonlinear function without the need to specify explicitly the form of the approximating function.

For AT and ST, we used a partial spline model (Wahba, 1990) with thinning intensities as the parametric part. We used a cubic spline to model the temporal trend non-parametrically. Since ATR data displayed a large variation among the four monitoring points for each of the treatments, we treated the four monitoring points for each treatment as a random effect. For the ATR model, the parametric parts included the thinning intensity and an interaction term between the linear temporal trend and the thinning intensity. A periodic smoothing spline was used to model the temporal trend. For the STR model, we used a linear mixed-effects model to analyze the data, with monitoring points as a random effect and both thinning intensity and linear temporal trend as fixed effects. For the SWP model, the parametric parts included the thinning intensity and a linear temporal trend. Monitoring points were treated as random. We used a periodic smoothing spline to model the temporal trend. For the VPD model, the parametric parts included thinning intensity, linear temporal trend, and their interactions. We used a periodic spline to model the temporal trend. Monitoring points were treated random. The models were judged to provide the best fit.

For semiparametric smoothing spline models, we used the assist package (Wang and Ke, 2004) of $R$ (R Development Core Team, 2006) to analyze the data. The nlme package (Pinheiro et al., 2006) of $R$ was used for the linear mixed-effects model. For each model, correlations and heteroscedasticity among the data were accounted for by the approaches given in Pinheiro and Bates (2000). Residuals diagnostics indicated that none of the residuals from the fitted models significantly violated the independence, equal variance, and normality assumptions. Details on using semiparametric smoothing splines to analyze four of the six microclimatic variables can be found in Guan et al. (2006).

\section{Results}

Both AT and ST exhibited a similar pattern across the 2-year monitoring period (Figs. 1 and 2) and both reflected the air temperature pattern observed at the Guanwu Weather Station (Fig. 3). The fitted results agreed with the observed data for 




Fig. 2. Observed mean (O), overall mean (dashed line), and model fitted (solid line) monthly average soil temperatures from February 2002 to January 2004 for the four thinning treatments. For each month, the overall mean is the average of the observed means.

both variables (coefficient of determination, $R^{2}>0.95$ for both variables). The monthly average soil temperatures were about the same as the air temperatures, suggesting that soil did not have a dampening effect on temperature. Over the 2-year period, both AT and ST at the strongly thinned stand were about

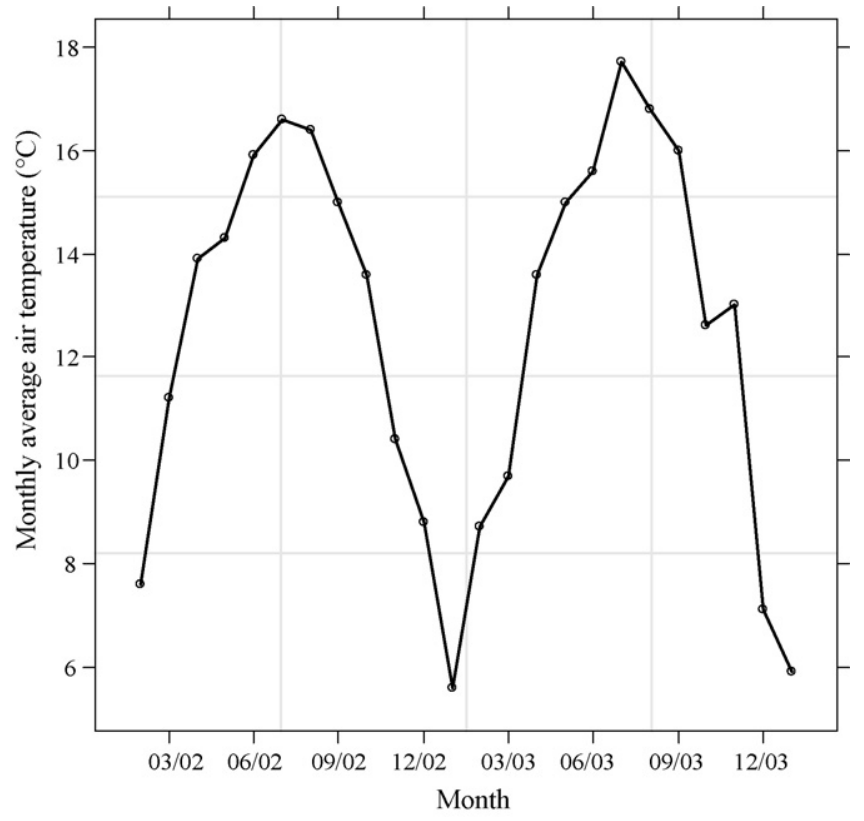

Fig. 3. Monthly average air temperatures at the Guanwu Weather Station from February 2002 to January 2004.
0.6 and $0.7^{\circ} \mathrm{C}$ higher than at the control. For the other two thinning treatments, the two variables were about the same as those for the control (Table 1).

For ATR, the $R^{2}$ between the fitted and the observed values was 0.64 , suggesting that the model was appropriate. The fitted model exhibited a prominent sinusoidal trend for all of the treatments (Fig. 4). This mainly reflected the relationship between the monthly precipitation and air temperature range in the study region (Fig. 5). The weather records at the Guanwu Weather Station during the study period indicated that the monthly precipitation and average temperature range were negatively correlated (Pearson's $r=-0.74, p<0.001$ ). Thus, in 2002, the ATRs steadily declined from spring to late summer (wet season) and then rose toward the end of that year. In 2003, the trend during the spring was similar, but due to the severe summer drought of that year, the ATRs peaked in July, and then declined again toward the end of the year. The ATRs of the unthinned stand also revealed the effects of forests on modulating air temperature ranges. For the unthinned stand, the ATRs were about $2-3{ }^{\circ} \mathrm{C}$ lower than those observed at the Guanwu Weather Station (Fig. 5), and its month-to-month variations were also smaller.

The effects of thinning on ATR can be clearly recognized in Fig. 4. Firstly, all thinned stands had a higher ATR value than that of the control in the beginning. The differences gradually narrowed toward the end of 2003, except for the strongly thinned stand, which still had a rather high ATR value at the end. Secondly, the variations in ATR for the thinned stands were 
Table 1

The effects of thinning intensity on the six microclimatic variables

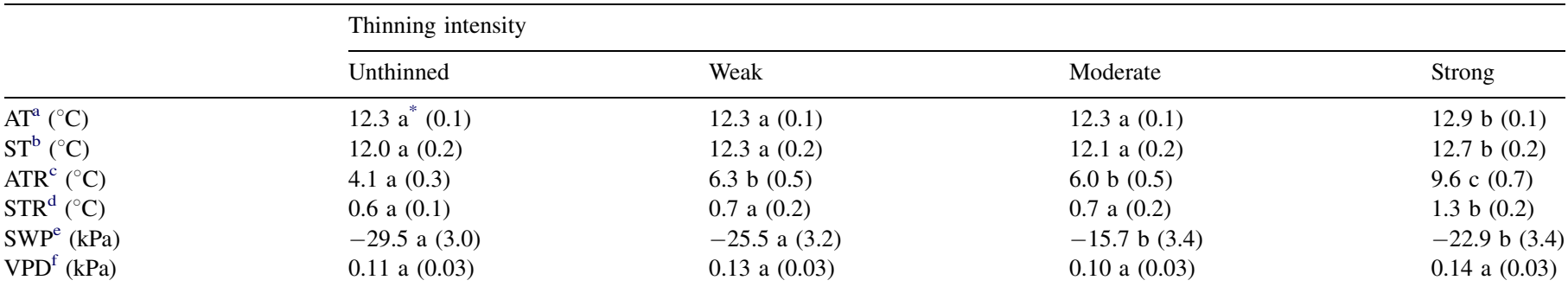

Numbers in the table are the model estimated overall means and standard errors (in parentheses).

${ }^{\text {a }}$ Monthly average air temperature measured at $70 \mathrm{~cm}$ above the soil surface.

b Monthly average soil temperature measured at $10 \mathrm{~cm}$ below the soil surface.

${ }^{\mathrm{c}}$ Monthly air temperature range measured at $70 \mathrm{~cm}$ above the soil surface.

d Monthly soil temperature range measured at $10 \mathrm{~cm}$ below the soil surface.

e Monthly soil water potential measured at $10 \mathrm{~cm}$ below the soil surface.

${ }^{\mathrm{f}}$ Monthly average water vapor pressure deficit measured at $70 \mathrm{~cm}$ above the soil surface.

* Means followed by different letters in the same row differ significantly $(p<0.05)$ based on a $t$-test.

also larger, especially for the strongly thinned stand. Thirdly, ATRs at the strongly thinned stand narrowed at a much faster rate as time progressed.

Averaged over the 2-year period, all ATRs of the thinned stands were significantly higher than that of the unthinned stand ( $p<0.005$ for all the thinned stands, Table 1). In comparison with the other two thinned stands, the strongly thinned stand had a significantly higher ATR value throughout the monitoring period. The significant $(p<0.001)$ parametric interaction term between thinning intensity and time suggested that the downward rates varied among the treatments, with the strongly thinned stand having the highest downward rate, followed by the weakly thinned stand. The rates for the moderately thinned and unthinned stands were about equal.

The temporal trend of STR also mirrored the regional pattern between precipitation and air temperature range (Fig. 5). All thinned stands exhibited larger STR variations, especially the strongly thinned stand (Fig. 6). However, unlike the ATR, variations within all treatments were smaller, likely due to the damping effects of soil. The $R^{2}$ between the fitted and observed

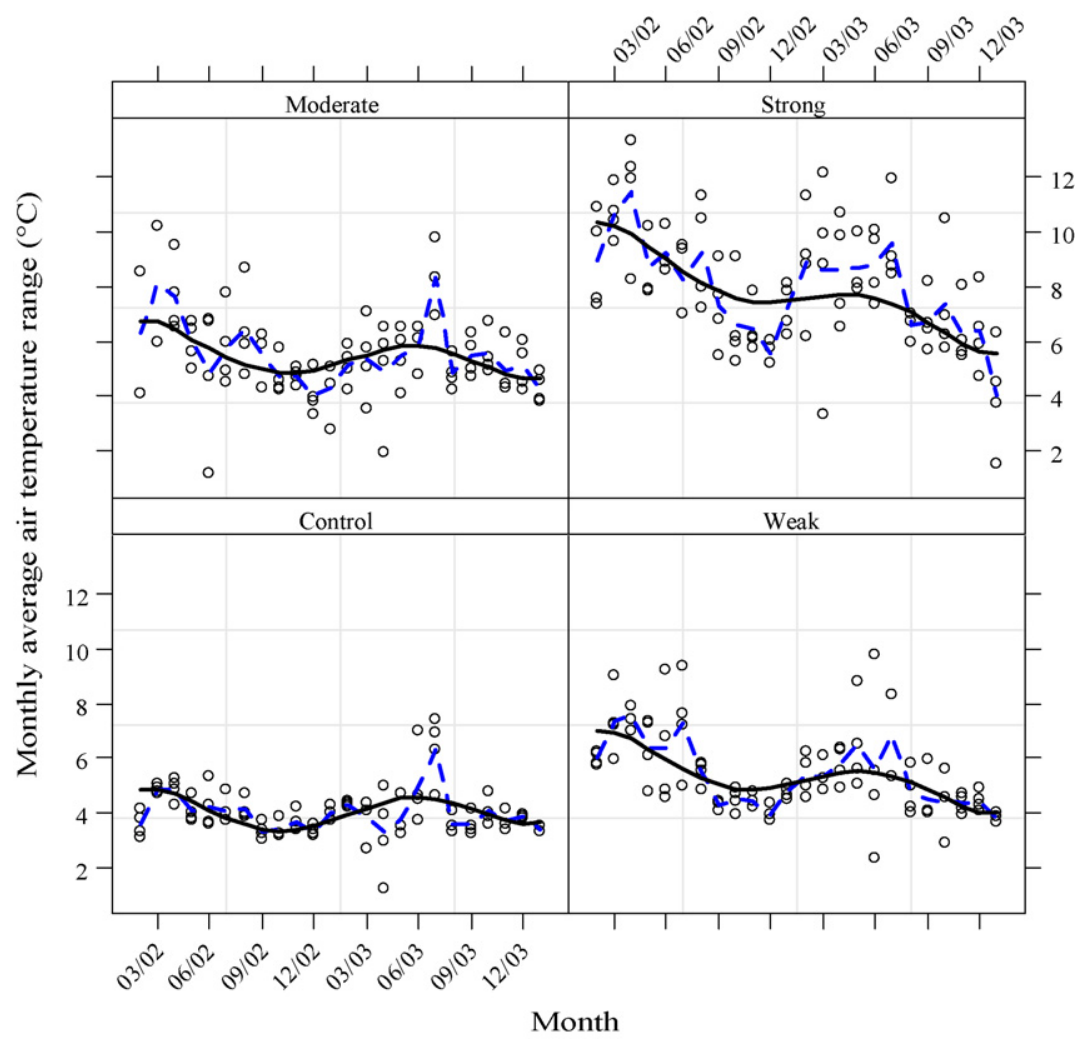

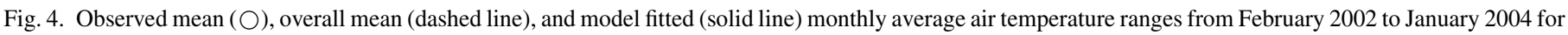
the four thinning treatments. For each month, the overall mean is the average of the observed means. 


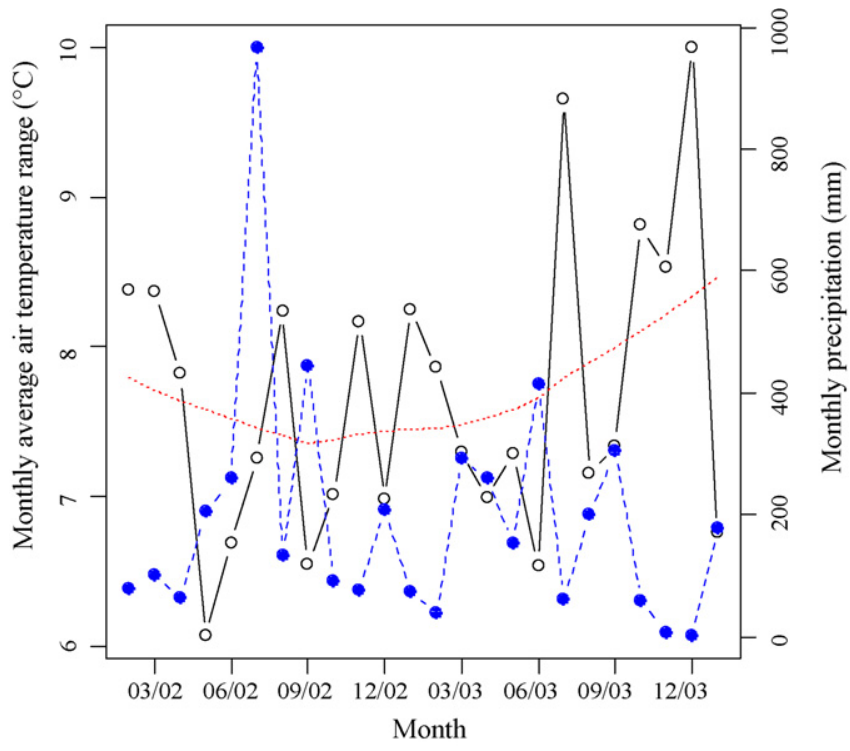

Fig. 5. Monthly average air temperature ranges ( $\bigcirc$ and solid line) and monthly precipitation ( and dashed line) at the Guanwu Weather Station from February 2002 to January 2004. The dotted line is a loess fitted temporal trend for air temperature ranges.

values was about 0.47 . As in the case of ST, only the strongly thinned stand had an overall mean that was significantly higher than that of the control (difference was $0.7{ }^{\circ} \mathrm{C}, p<0.005$ ). Another feature suggested by the fitted model was that STRs for all stands had slight, but significant increasing trends (average rate about $0.007{ }^{\circ} \mathrm{C}$ per month, $p<0.005$ ) during the study period, which again reflected the regional trend in air temperature range (Fig. 5). Although such an increasing trend was also detected in ATR, it was masked by the prominent downward trends.

For SWP, the $R^{2}$ between the model fitted values and the observed values was 0.5 , which indicated that the model fit was moderately adequate. The dominant feature in SWP, as revealed by the fitted model, was the downward trend from the beginning to the end of the monitoring period (Fig. 7), which reflected the drought conditions during that period. Among the four stands, the moderately thinned stand had the highest SWP, followed by the strongly thinned stand (Table 1). Further, SWPs for both stands were significantly higher than that of the control ( $p<0.001$, and $p=0.044$, respectively). An important feature in Fig. 7 was that all thinned stands had higher SWPs during the severe summer drought of 2003.

Of the six variables, VPD was the most difficult to analyze. The $R^{2}$ between the fitted and the observed value was 0.40 . Nonetheless, the fitted model revealed several important features (Fig. 8). Firstly, averaged over the 2-year period, the differences in VPD among the treatments were small (Table 1). Secondly, VPD for the unthinned and weakly stands showed a slight but significant upward temporal trend $(0.008 \mathrm{kPa}$ per month, $p<0.001)$ over the study period, mainly due to the drought conditions. The upward rate amounted to about 6-7\% per month of the overall averages. For both the strongly and moderately thinned stands, the upward rates were 0.004 and $0.005 \mathrm{kPa}$ per month, respectively, which

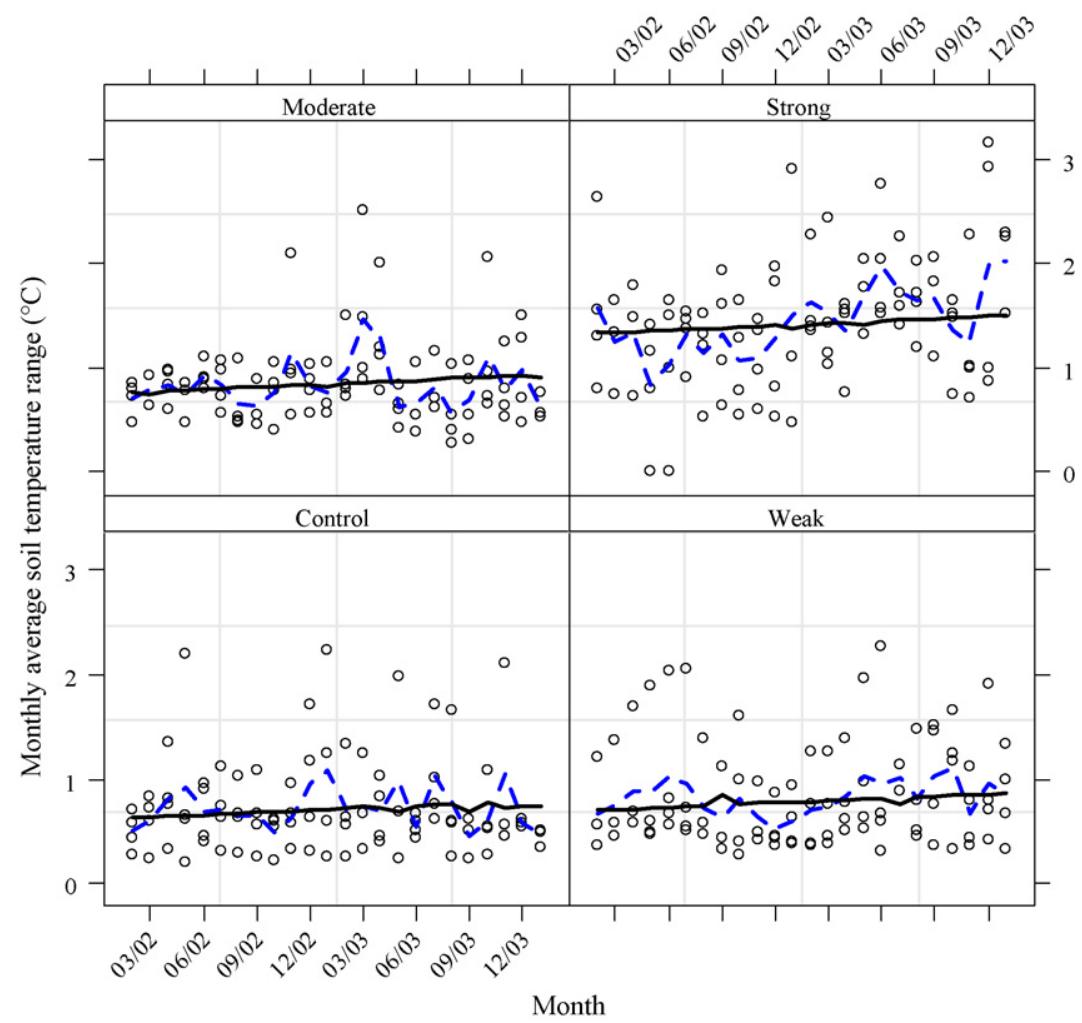

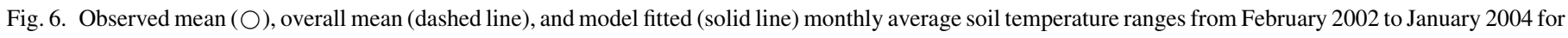
the four thinning treatments. For each month, the overall mean is the average of the observed means. 




Fig. 7. Observed mean $(\bigcirc)$, overall mean (dashed line), and model fitted (solid line) monthly average soil water potential from February 2002 to January 2004 for the four thinning treatments. Soil water potentials were measured at $10 \mathrm{~cm}$ below soil surface. For each month, the overall mean is the average of the observed means.

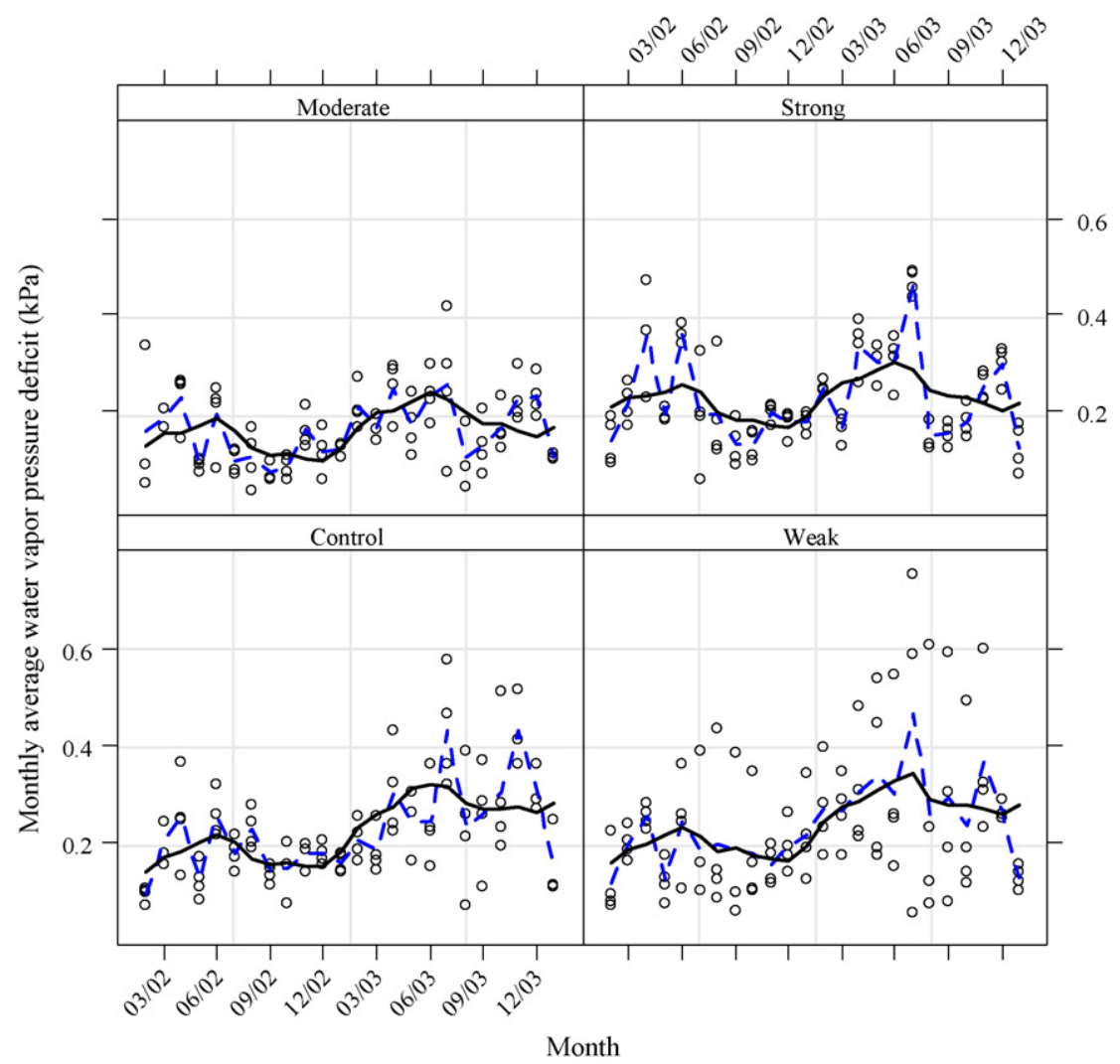

Fig. 8. Observed mean $(\bigcirc)$, overall mean (dashed line), and model fitted (solid line) monthly average air water pressures deficit from February 2002 to January 2004 for the four thinning treatments. For each month, the overall mean is the average of the observed means. 
were all significantly slower than that for the unthinned and weakly thinned stands ( $p<0.01$, and $p=0.032$, respectively).

\section{Discussion}

The responses of the six microclimatic variables over the monitoring period clearly show the hierarchical influences of the regional climatic factors and thinning. They were first controlled by higher-level factors, such as regional temperature and precipitation trends. Topography also contributed in shaping the temporal trends (Holst et al., 2005). For instance, because of its north-facing aspect, the moderately thinned stand had the highest SWP and the lowest VPD (Table 1).

Our study also revealed the effects of thinning and its interactions with the regional climatic trends on the six microclimatic variables. In general, thinned stands had higher air and soil temperatures (Table 1). The reason for this is that the opening up of the canopies enables more direct incident radiation to reach into the stands. The thinned stands also tended to have higher air and soil temperature ranges, especially the strongly thinned stand. The month-to-month variations of the two variables also tended to be greater for the thinned stands. Our results are consistent with other thinning studies (e.g., Hungerford and Babbitt, 1987; Thibodeau et al., 2000; Prévost and Pothier, 2003; Frey et al., 2003). Significantly higher temperature ranges in the thinned stand are likely due to greater heat gain during daytime and greater heat loss during nighttime (Groot and Carlson, 1996). Greater month-to-month variations in air and soil temperature ranges for the thinned stands are likely due to structural heterogeneity created by thinning (Heithecker and Halpern, 2006).

Higher temperatures and temperature ranges have been reported to have positive and significant effects on both the emergence of light demanding species seedlings (Wetzel and Burgess, 2001; Prévost and Pothier, 2003; Zhu et al., 2003) and soil mineralization rates (e.g., Thibodeau et al., 2000; Bauhus et al., 2001; Prévost and Pothier, 2003; Frey et al., 2003). We also observed such phenomena. After thinning, a large number of seedlings from several light demanding species, particularly Japanese cedar, Taiwan sassafras (Sassafras randaiense Rehder), and Taiwan spicebush (Litsea cubeba Persoon), emerged in the strongly and moderately thinned stands (Weng, 2004). During the study period, both the understory species richness and the diversity increased in the strongly and moderately thinned stands (Weng, 2004). Since the root lengths of those newly emerged light-demanding seedlings were all at least $4 \mathrm{~cm}$, we believe that their emergences were mainly due to higher temperatures and higher temperature ranges (Bazzaz, 2003). We also observed a higher nitrogen mineralization rate, especially the nitrification rate, in the strongly thinned stand (M. K. Wang, pers. comm.) Such a higher rate could also be the result of higher temperatures and temperature ranges (Thibodeau et al., 2000; Breuer et al., 2002).

However, this study also shows that the air temperature ranges of the thinned stands returned to the pre-thinning status rather quickly (Fig. 4), although the canopies remained relatively open. This could be due to the development of abundant understory vegetation in the thinned stands, especially the strongly thinned stand, which would then modulate the air temperature and buffer the temperature range above the soil surface. Thus, we would expect that both ATRs and STRs of the strongly thinned stand to return to their prethinning conditions within the next two to three years because of an abundant understory vegetation and a recovery of the canopy.

Many thinning experiments have shown that, with less precipitation being intercepted and fewer trees transpiring, thinned stands usually have higher soil water potential than do the unthinned ones (e.g., Aussenac, 2000). The contrast between the thinned and unthinned stands should be especially noticeable during a drought (Aussenac and Granier, 1988). Our study confirms this trend. Probably because of thinning and its aspect, the SWPs of the moderately thinned stand were significantly higher than those of both the unthinned and weakly thinned stands during the severe summer drought of 2003. The strongly thinned stand also showed a similar trend, although less dramatic. A higher average soil water potential for the strongly thinned stand may also contribute to a higher nitrogen mineralization rate in that stand (Doran et al., 1990).

With respect to the mean responses, VPD was the only variable for which we did not detect a significant difference between the thinned and unthinned stands (Table 1). Meyer et al. (2001) and Vesala et al. (2005) all reported that thinning had no significant effect on water vapor pressure deficit in their studies. In our case, one likely reason is that the study area is located within the cloud belt of northern Taiwan. Within that belt, fogs frequently form during the afternoon, even in dry seasons. Thus, VPDs were small throughout the study period, even during the severe summer and winter droughts of 2003 (Fig. 8). However, our study also revealed that thinning and higher-level microclimate controlling factors did interact on this variable. The strongly and the moderately thinned stands had slower upward rates than that for the unthinned and weakly thinned stands, but for different reasons. For the strongly thinned stand, the slower rate was likely due to the higher average air temperature that resulted from thinning. For the moderately thinned stand, the slower rate was more likely due to its aspect. Based on the results from SWP and VPD, the residual trees in the strongly and moderately thinned stands experienced less water stress than their counterparts in the other two stands did during the study period.

In this study, the strong thinning intensity had the most significant effect in altering microclimates. In comparison with the unthinned stand, the other two thinning treatments produced little or no effects. For the moderately thinned stand, even with $55 \%$ of the stems removed (corresponding to $36 \%$ of basal area), we could detect no effects of thinning on microclimates, except for SWP. We believe that the results were mainly due to the north-facing aspect of the stand. For the weakly thinned stand, no differences in results were expected. Although about $40 \%$ of the stems were removed from the weakly thinned stand, only about $15 \%$ of the basal area was removed because of the thinning-from-below approach. The openings created by the 
weak thinning were thus all relatively small. In terms of species richness, the weakly thinned stand was also similar to the control. Therefore, if we want to use thinning as a tool to promote biodiversity for Taiwan's Japanese cedar plantations, a stronger thinning intensity is recommended.

Although monitoring microclimate is an integral part of any thinning experiment, only a few studies have attempted to separate and evaluate the relative importance of regional climatic trends and thinning on microclimatic responses. We believe that this failing is due mainly to the difficulty in modeling temporal response trends. Our study has demonstrated that, with appropriate statistical approaches, we can not only reveal interesting temporal trends, but also separate the influences that are due to higher-level climatic factors from those due to thinning. This will lead to a better understanding of how thinning truly affects microclimates.

\section{Acknowledgements}

This study was supported by a grant from Taiwan Forestry Bureau, Council of Agriculture, Taiwan. Additional funding for B.T. Guan and T.Y. Chang from the National Science Council of Taiwan (NSC-93-2621-B-002-008) is also acknowledged. Field assistances from personnel of Hsin-Chu Forest District of Taiwan Forestry Bureau are greatly appreciated. We also appreciate the comments from two reviewers.

\section{References}

Aussenac, G., Granier, A., 1988. Effects of thinning on water stress and growth in Douglas fir. Can. J. For. Res. 1, 100-105.

Aussenac, G., 2000. Interaction between forest stands and microclimate: ecophysiological aspects and consequences of silviculture. Ann. For. Sci. 57, 287-301.

Bauhus, J., Aubin, I., Messier, C., Connell, M., 2001. Composition, structure, light attenuation and nutrient content of the understory vegetation in a Eucalyptus sieberi regrowth stand 6 years after thinning and fertilisation. For. Ecol. Manage. 144, 275-286.

Bazzaz, F.A., 2003. Plants in Changing Environments: Linking Physiological, Population, and Community Ecology, 2nd ed. Cambridge University Press, Cambridge.

Breuer, L., Kiese, R., Butterbach-Bahl, K., 2002. Temperature and moisture effects on nitrification rates in tropical rain-forest soils. Soil Sci. Soc. Am. J. 66, 834-844.

Buck, A.L., 1981. New equations for computing vapor pressure and enhancement factor. J. Appl. Meteorol. 20, 1527-1532.

Doran, J.W., Mielke, L.N., Power, J.F., 1990. Microbial activity as regulated by soil water-filled pore space. In: Trans. 14th international congress of soil science, vol. III, Kyoto, Japan, pp. 94-99.

Eubank, R.L., 1999. Nonparametric Regression and Spline Smoothing, 2nd ed. Marcel Dekker, New York.

Frey, B.R., Lieffers, V.J., Munson, A.D., Blenis, P.V., 2003. The influence of partial harvesting and forest floor disturbance on nutrient availability and understory vegetation in boreal mixedwoods. Can. J. For. Res. 33, 11801188.

Green, P.J., Silverman, B.W., 1994. Nonparametric Regression and Generalized Linear Models: A Roughness Penalty Approach. Chapman \& Hall, New York.

Groot, A., Carlson, D.W., 1996. Influence of shelter on night temperatures, frost damage, and bud break of white spruce seedlings. Can. J. For. Res. 26, 1531-1538.
Guan, B.T., Weng, S.-H., Kuo, S.-R., Chang, T. -Y, Hsu, H.-W., Shen, C.-W., 2006. Analyzing the effects of stand thinning on microclimates with semiparametric smoothing splines. Can. J. For. Res. 36, 16411648 .

Hagar, J., Howlin, S., Canio, L., 2004. Short-term response of songbirds to experimental thinning of young Douglas-fir forests in the Oregon Cascades. For. Ecol. Manage. 199, 333-347.

Hanley, T.A., 2005. Potential management of young-growth stands for understory vegetation and wildlife habitat in southeastern Alaska. Land. Urb. Plan. $72,95-112$

Heithecker, T.D., Halpern, C.B., 2006. Variation in microclimate associated with dispersed-retention harvests in coniferous forests of western Washington. For. Ecol. Manage. 226, 60-71.

Holst, T., Mayer, H., Schindler, D., 2004. Microclimate within beech stands. Part II. Thermal conditions. Eur. J. Forest Res. 123, 13-28.

Holst, T., Rost, J., Mayer, H., 2005. Net radiation balance for two forested slopes on opposite sides of a valley. Int. J. Biometeorol. 49, 275-284.

Hungerford, R.D., Babbitt, R.E., 1987. Overstory removal and residue treatments affect soil surface, air, and soil temperature: implications for seedling survival. USDA Forest Service Research Paper INT-377. Intermountain Forest and Range Experiment Station, Ogden, UT, p. 19.

Ke, C., Wang, Y., 2001. Semi-parametric nonlinear mixed effects models and their applications. J. Amer. Stat. Assoc. 96, 1272-1298.

Lindh, B.C., Muir, P.S., 2004. Understory vegetation in young Douglas-fir forests: does thinning help restore old-growth composition? For Ecol. Manage. 192, 285-296.

MacCracken, J.G., 2005. Effects of uneven-aged timber harvest on forest floor vertebrates in the Cascade Mountains of southern Washington. For. Ecol. Manage. 208, 123-135.

Meyer, C.L., Sisk, T.D., Covington, W.W., 2001. Microclimatic changes induced by ecological restoration of ponderosa pine forests in northern Arizona. Restor. Ecol. 9, 443-452.

Muir, P.S., Mattingly, R.L., Tappeiner, J.C., Bailey, J.D., Elliot, W.E., Hagar, J.C., Miller, J.C., Peterson, E.B., Starkey, E.E., 2002. Managing for biodiversity in young Douglas-fir forests of western Oregon. U.S. Geologial Survey Biological Resources Division, Biol. Sci. Rep. USGS/BRD/BSR2002-0006.

Pinheiro, J.C., Bates, D.M., 2000. Mixed-Effects Models in S and S-Plus. Springer, New York.

Pinheiro, J.C., Bates, D.M., DebRoy, S., Sarkar, D., 2006. nlme: linear and nonlinear mixed effects models. R package version 3, 1-76.

Prévost, M., Pothier, D., 2003. Partial cuts in a trembling aspen-conifer stand: effects on microenvironmental conditions and regeneration dynamics. Can. J. For. Res. 33, 1-15.

R Development Core Team, 2006. R: A language and environment for statistical computing. R Foundation for Statistical Computing. Vienna, Austria.

Sullivan, T.P., Sullivan, D.S., Lindgren, P.M.F., 2001. Stand structure and small mammals in young lodgepole pine forest: 10-year results after thinning. Ecol. Appl. 11, 1151-1173.

Sullivan, T.P., Sullivan, D.S., Lindgren, P.M.F., Boateng, J.O., 2002. Influence of conventional and chemical thinning on stand structure and diversity of plant and mammal communities in young lodgepole pine forest. For. Ecol. Manage. 170, 173-187.

Sullivan, T.P., Sullivan, D.S., Lindgren, Ransome, D.B., 2005. Long-term responses of ecosystem components to stand thinning in young lodgepole pine forest II. Diversity and population dynamics of forest floor small mammals. For. Ecol. Manage. 205, 1-14.

Thibodeau, L., Raymond, P., Camire, C., Munson, A.D., 2000. Impact of precommercial thinning in balsam fir stands on soil nitrogen dynamics, microbial biomass, decomposition, and foliar nutrition. Can. J. For. Res. 30, 229-238.

Vesala, T., Suni, T., Rannik, Ü., Keronen, P., Markkanen, T., Sevanto, S., Grönholm, T., Kulmala, M., Ojansuu, R., Uotila, A., Levula, J., Mäkelä, A., Pumpanen, J., Kolari, P., Berninger, F., Ilvesniemi, H., Nikinmaa, E., Hari, P., 2005. The effect of thinning on surface fluxes in a boreal forest. Glob. Biogeochem. Cycle 19, GB2001, doi:10.1029/2004GB002316.

Wahba, G., 1990. Spline Models for Observational Data. SIAM, Philadelphia. 
Wang, Y., Ke, C., 2004. ASSIST: A Suite of S Functions Implementing Spline Smoothing Techniques. University of California, Santa Barbara.

Weng, S.H., 2004. Comparisons of microenvironmental and vegetation changes after different thinning intensities in a sugi (Cryptomeria japonica) plantation at Guanwu, northern Taiwan. M.S. thesis, Dept. Forestry, National Taiwan University, Taipei, Taiwan. (in Chinese, with English abstract).
Wetzel, S., Burgess, D., 2001. Understory environment and vegetation response after partial cutting and site preparation in Pinus strobus L. stands. For. Ecol. Manage. 151, 43-59.

Zhu, J.-J., Matsuzaki, T., Lee, F.-Q., Gonda, Y., 2003. Effect of gap size created by thinning on seedling emergency, survival and establishment in a costal forest. For. Ecol. Manage. 182, 339-354. 